\title{
Membuat Bussines Model Canvas (Bmc) Untuk Start Up Di Kelurahan Bambu Apus Jakarta Timur
}

\author{
Dinni Agustin, Sigit Cahyono, Tafrizi, Agusti Evianasari, Nurminingsih \\ Fakultas Manajemen dan Bisnis Universitas Respati Indonesia \\ Email : dinniagustin@urindo.ac.id
}

\begin{abstract}
Abstrak
Pola pikir masyarakat di era globalisasi telah banyak berubah, yang pada awalnya berlomba-lomba ingin menjadi karyawan, namun saat ini banyak yang menginginkan atau bercitacita menjadi enterpreneur (wirausaha). Akan tetapi setelah mereka terjun langsung dan menekuninya bidang usaha ternyata banyak kendala/hambatan yang mereka alami sebagai enterpreneur. Kesulitan dalam bidang segmentasi konsumen, ketersediaan bahan baku, modal dan pemasalahan lainnya adalah salah satu contoh yang mereka hadapi. Untuk dapat menghadapi masalah tersebut diperlukan pelatihan dalam pembuatan rencana usaha dengan menggunakan Bussiness Model Canvas (BMC). Tujuan dari pelatihan adalah agar peserta dapat mengatasi jika menemukan kesulitan dalam berbisnis. BMC dapat menggambarkan usaha apa yang sedang dijalankan secara menyeluruh dari berbagai aspek. Banyak hal yang belum terpikirkan oleh pengusaha pemula akan tercakup semuanya dalam BMC secara lengkap. Metode yang digunakan dalam pelaksanaan kegiatan pelatihan adalah observasi, wawancara secara langsung, penyuluhan dan melaksanakan demonstrasi di hadapan peserta. Hasil yang dicapai adalah para pelaku start up mendapatkan pengetahuan tentang BMC dan mampu membuat perencanaan bisnis dengan menggunakan model BMC.
\end{abstract}

Kata kunci : Business Model Canvas (BMC), start up, pelatihan

\begin{abstract}
The mindset of people in the era of globalization has changed a lot, which at first was competing to become employees, but nowadays many aspire to become entrepreneurs. However, after they jumped in and worked in the business sector, it turned out that they experienced many obstacles as entrepreneurs. Difficulties in consumer segmentation, availability of raw materials, capital, and other problems are examples they face. To be able to deal with these problems requires training in making a business plan using the Business Model Canvas (BMC). The purpose of the training is that participants can overcome if they encounter difficulties in doing business. $\mathrm{BMC}$ can describe what business is being carried out from various aspects. Many things that have not been thought of by a budding entrepreneur will all be covered in a complete BMC. The methods used in the implementation of training activities are observation, direct interviews, counseling, and carrying out demonstrations to the participants. The results achieved are that start-ups get knowledge about BMC and are able to make business plans using the BMC model.
\end{abstract}

Keywords: Business Model Canvas (BMC), start up, training

http://ejournal.urindo.ac.id/index.php/PAMAS

Article History :

Submitted 15 April 2021, Accepted 28 April 2021, Published 30 April 2021 


\section{Pendahuluan}

Bagaimana membangun sebuah bisnis tentu memerlukan suatu proses, artinya dalam bisnis tidak ada bisnis yang dapat langsung menjadi besar dan maju secara tiba-tiba tanpa memerlukan usaha dan perjuangan. Pelaku bisnis seperti pengusaha UMKM atau yang termasuk dalam kategori start-up akan merasakan betapa kerasnya suatu perjuangan untuk mengembangkan sebuah bisnis. Oleh karena itu sangat penting mengapa pelaku start-up harus memiliki perencanaan untuk sebuah model usaha/business model, hal ini diperlukan agar dapat memetakan gambaran bisnis secara terencana dan sistematis, yang nantinya dapat digunakan untuk pengambilan keputusan untuk pengembangan pengelolaan usaha secara strategis. Namun tidak semua pengusaha pemula (bahkan yang sudah lama berbisnis sekalipun) tahu apa itu business model, padahal sebuah usaha start-up atau usaha rintisan memerlukan sebuah rencana strategis yang dapat menunjang jalannya sebuah usaha kedepan. Untuk itu, pengelolaan usaha model kanvas yang diusulkan ini bisa menjadi salah satu cara untuk menciptakan atau mengembangkan strategi bisnis ke depan.

Business Model Canvas (BMC) yang dikembangkan oleh Alexander Osterwalder adalah sebuah alat (tools) yang digunakan guna menyederhanakan konsep model bisnis yang semula rumit dan kompleks diupayakan agar dapat menjadi mudah dan bisa dimanfaatkan oleh sebuah organisasi/ wirausahawan untuk membuat, mendiskusikan, dan memahami sebuah model bisnis dengan lebih sistematis dan efisien, sehingga bisa menjangkau target pasarnya secara efektif. Dengan model bisnis kanvas dapat menjelaskan bagaimana sebuah organisasi menciptakan, menawarkan serta menangkap nilai (value) sebuah usaha. Selain itu model bisnis juga bisa didefinisikan sebagai paparan strategi yang harus dibuat oleh pelaku usaha sebelum mulai berkompetisi dengan pelaku usaha lainnya. Banyak sekali strategi yang harus dijelaskan dalam mengelola sebuah model bisnis karena strategi bisnis tersebut berhubungan dengan banyak aspek dalam melakukan sebuah usaha.

Proses membuat strategi ini yang kemudian sangat penting untuk diterapkan pada pengusaha start up. Membuat konsep usaha dengan menggunakan bisnis model kanvas ini pada dasarnya adalah kita membuat perencanaan secara tertulis mengenai masa depan bisnis 
pengusaha start up. Dengan demikian konsep ini akan menyakinkan dan memampukan pengusaha start up, untuk dapat digunakan untuk meningkatkan taraf kesejahteraan ekonominya.

Pelaksanaan pelatihan yang kami selenggarakan tidak memerlukan jenjang atau level pemahaman yang tinggi dari pelaku pengusaha start up, pelatihan ini dapat diterima oleh semua kalangan dengan latar pendidikan berbeda. Hal ini dikarenakan tools (alat) bisnis model kanvas sangat memudahkan peserta dalam mempetakan bisnisnya, selain itu juga sudah didukung dengan petunjuk yang terdapat pada tools yang sudah tersedia.

Berdasarkan hal tersebut Program Studi Ilmu Administrasi Niaga Fakultas Manajemen Bisnis melaksakan kegiatan Pengadian Kepada Masyarakat dengan tema "Pelatihan Membuat Business Model Canvas (BMC) nntuk Start Up di Universitas Respati Indonesia".

\section{Tujuan}

Untuk melakukan pemetaan pelaku usaha UKM ataupun menengah keatas, bagaimana mengembangkan usaha untuk mendapatkan laba usaha yang maksimal, dan menciptakan bisnis yang dapat bertahan dalam jangka waktu lama.

\section{Metoda}

Metoda yang kami gunakan adalah dengan mengikut sertakan secara langsung pelaku UMKM sebanyak 25 orang dari pelaku UMKM yang berada di Kelurahan Bambu Apus, Cipayung, Jakarta Timur.

Mengingat pandemi covid-19 dimana diberlakukan jarak fisik maka kegiatan pelatihan dilakukan secara daring melalui aplikasi zoom. Pelatihan online selain diisi dengan paparan materi pelatihan bagaimana membuat BMC, menyiapkan ijin usaha dan memasarkan produk. Diselenggarakan juga sesi diskusi dan tanya jawab, demonstrasi, dan tutorial kepada peserta pelatihan agar mereka dapat dengan mudah menerapkan dalam mempersiapkan bisnisnya.

\subsection{Tahapan persiapan}

Proses pada tahap persiapan adalah semua data di identifikasi dan telah disetujui untuk dilaksanakan. Untuk mendukung kelancaran serta efektifitas program pengabdian kepada 
Jurnal Pelayanan dan Pengabdian Masyarakat (PAMAS)

masyarakat ini kami memberikan usulan untuk memecahkan masalah pelaku usaha pemula sebagai berikut:

1. Pengabdi harus mempunyai kemampuan secara teori dan praktek yang memadai dalam pelatihan pembuatan BMC.

2. Menyiapkan dokumen perijinan serta melibatkan pihak-pihak terkait dalam hal ini Kelurahan Bambu Apus

3. Materi pelatihan berupa pemberian informasi mengenai pembuatan $B M C$, menyiapkan ijin usaha dan pemasaran

4. Evaluasi program meliputi: persiapan kegiatan, pelaksanaan, materi, pelatih, peserta dan penyelenggaraan kegiatan.

5. Output pelatihan adalah proposal yang dibuat oleh peserta pelatihan yang siap untuk dilaksanakan

\subsection{Waktu dan tempat pelaksanaan}

Kegiatan pelatihan diselenggarakan pada hari Sabtu, 27 Juni 2020, pukul 10.00-12.30 WIB. Karena kegiatan ini dilaksanakan secara daring maka kami dapat memperluas sasaran peserta pelatihan yang ditargetkan sebanyak 200 orang peserta.

Tempat pelaksanaan pelatihan secara daring diselenggarakan di kampus Universitas Respati Indonesia dengan memberlakukan jarak fisik, sedangkan peserta mengikuti kegiatan ini dari tempat mereka masing-masing.

\subsection{Tahapan Pelaporan}

Untuk tahap pelaporan kegiatan Pengabdian kepada Masyarakat dilaksanakan pada akhir kegiatan dengan maksud agar dapat merangkum hasil serta membuat rencana tindak lanjut.

\subsection{Hasil Kegiatan}

“Pelatihan Membuat Bussines Model Canvas (BMC) untuk Start Up di Kelurahan Bambu Apus Jakarta Timur", diselenggarakan webinar pada hari Sabtu, 27 Juni 2020 pukul 
10.00-12.30 WIB, melalui kegiatan webinar dengan aplikasi zoom, diikuti sebanyak 281 orang peserta dari target 200 orang peserta. Luaran yang diharapkan dari pelatihan ini adalah proposal yang dibuat oleh peserta pelatihan yang siap untuk dilaksanakan

\subsubsection{Karakteristik peserta pelatihan}

Karakteristik peserta pelatihan dapat dilihat dari tingkat pendidikan seluruh peserta pelatihan dari Kelurahan Bambu Apus berasal dari tingkat pendidikan SD dan SMP, dengan perbedaan latar pendidikan tersebut, tentu menyebabkan adanya perbedaan pemahaman materi yang disampaikanoleh narasumber, terlihat dari pertanyaan-pertanyaan yang diajukan pada saat diskusi tanya jawab.

\subsubsection{Tanggapan/respon peserta pelatihan}

Penyampaian materi model bisnis canvas dilengkapi dengan simulasi dan diskusi selama selama pelatihan berlangsung. Dari hasil evaluasi sebelum dan sesudah materi disampaikan, terlihat bahwa tanggapan dari peserta pelatihan cukup baik, terlihat dengan besarnya minat peserta dalam mengajukan pertanyaan terkait di dalam setiap sesi diskusi.

\subsubsection{Solusi yang ditawarkan}

Pada penyelenggaraan kegiatan pelatihan dalam pengabdian kepada masyarakat dari Fakultas Manajemen dan Bisnis Universitas Respati Indonesia ini adalah merupakan langkah awal dalam mendukung pengembangan potensi pelaku usaha kreatif dan start-up di Kelurahan Bambu Apus. Di dalam kegiatan ini kami mencoba menawarkan solusi kepada peserta pelatihan antara lain sebagai berikut:

1. Menjabarkan apa itu Bisnis Model Kanvas

2. Menjelaskan mengenai 9 (sembilan) elemen penting dalam bisnis model kanvas yaitu: 1 . customer segments, 2.value propotions, 3.channels, 4.customer relationships, 5.revenue streams, 6.key resources, 7.key activities, 8.key partners dan 9. cost structure.

3. Edukasi pelaku UMKM. Kegiatan ini dalam bentuk seminar yang direncanakan melibatkan semua unsur dalam pelaksanaan program,

4. Pemberian Pelatihan kepada pelaku UMKM, berupa Praktek aplikasi bisnis model kanvas. Dengan adanya pelatihan ini diharapkan pengetahuan akan meningkat, ketrampilan dalam pendampingan juga meningkat. 


\section{Simpulan}

Kegiatan usaha dengan memakai Business Model Canvas (BMC) merupakan gambaran yang dapat diterima oleh pelaku usaha tentang bagaimana sebuah pelaku usaha menciptakan, menangkap kemudian menghantarkan sebuah nilai usaha. Penggunaan businnes model canvas (BMC) ini dapat diterapkan baik dalam usaha kecil dan menengah secara merata untuk mengembangkan usaha serta untuk mendapatkan keuntungan dari usaha yang dilakukan, juga untuk menciptakan karyawan dengan skill yang lebih baik, kemudian dapat membuat usaha bertahan lebih lama. Dalam kenyataannya bidang kewirausahaan yang ada di Indonesia belum dapat memaksimalkan keuntungan usaha, hal ini dapat kita lihat dari presentase jumlah wirausaha yang ada di Indonesia yang lebih rendah dibandingkan dengan negara ASEAN lainnya. Disamping itu masih banyak pelaku usaha di Indonesia yang masih kurang memahami cara untuk melakukan usaha/bisnis. Berkembangnya dunia bisnis di era globalisasi ini, membuat usaha menjadi lebih kompetitif, sehingga pelaku usaha perlu untuk mempelajari BUSINESS MODEL CANVAS (BMC) untuk meningkatkan usahanya secara maksimal, serta membuat usahanya dapat bertahan lama.

\section{Daftar Pustaka}

Aziz, N.F. 2015. Comparison of business model canvas (MBC) among the three consulting companies. Journal of computer science and information technology research. International islamis university Malaysia, v.3, issue 2, pp. 462-471.

Bastian, Coes. 2014. A Critically assessing the strengths and limitations ofthe business model canvas. Journal of master thesis business administration.

Chesborough, H.W. 2006. Open Business Models: How to thrive in the new innovation landscape. Boston: Harvard Business School Press.

Ferreira, Diogo. 2012. Financial Projection Based on Business Model Canvas. Computer and Engineering, Lisboa University.

Http://Nasional.Republika.Co.Id/Berita/Nasional/Umum/15/03/12/NI3i58-Jumlah-PengusahaIndonesia-Hanya-165-Persen 
Jurnal Pelayanan dan Pengabdian Masyarakat (PAMAS)

Https://Www.Maxmanroe.Com/Model-Bisnis-Kanvas-Memetakan-Alur-Bisnis-Lebih-simple-danefektif.html

John Willey \& Sons,Hoboken - NJ.Frans M, Royan. (2014), Bisnis model kanvas distributor. "Memetakan kinerja optimal distributor dan 30 kesalahan yang dilakukan.

Kasmir dan Jakfar. 2006. Studi Kelayakan Bisnis. Kencana, Jakarta.

Osterwalder, Alexander dan Yves Pigneur. 2010. Business Model Canvas Generation.

Priyono, F. 2005. Analisis Penerapan Business Model Canvas pada toko Moin Collection. Jurnal Manajemen Bisnis. Program Studi Manajemen Universitas Kristen Petra, v.3 no.2.

PPM Manajemen. 2012. Business model canvas: Penerapan di indonesia. Jakarta: PPM Manajemen. 